\title{
Nanofibrous vildagliptin-eluting stents enhance re-endothelialization and reduce neointimal formation in diabetes: in vitro and in vivo
}

This article was published in the following Dove Press journal: International Journal of Nanomedicine

\author{
Chen-Hung Lee' \\ Ming-Jer Hsieh' \\ Shang-Hung Chang' \\ Kuo-Chun Hung' \\ Chao-Jan Wang ${ }^{2}$ \\ Ming-Yi $\mathrm{Hsu}^{2}$ \\ Jyuhn-Huarng Juang ${ }^{3}$ \\ I-Chang Hsieh' \\ Ming-Shien Wen' \\ Shih-Jung Liu ${ }^{4,5}$ \\ 'Division of Cardiology, Department of \\ Internal Medicine, Chang Gung Memorial \\ Hospital-Linkou, Chang Gung University \\ College of Medicine, Linkou, Taiwan; \\ ${ }^{2}$ Department of Medical Imaging and \\ Intervention, Chang Gung Memorial \\ Hospital, Linkou, Tao-Yuan, Taiwan; \\ ${ }^{3}$ Division of Endocrinology and \\ Metabolism, Department of Internal \\ Medicine, Chang Gung University and \\ Chang Gung Memorial Hospital, Tao- \\ Yuan, Taiwan; ${ }^{4}$ Department of Mechanical \\ Engineering, Chang Gung University, Tao- \\ Yuan, Taiwan; ${ }^{5}$ Department of \\ Orthopedic Surgery, Chang Gung \\ Memorial Hospital-Linkou, Tao-Yuan \\ 33305, Taiwan
}

Background: The high lifetime risk of vascular disease is one of the important issues that plague patients with diabetes mellitus. Systemic oral vildagliptin administration favors endothelial recovery and inhibits smooth muscle cell (SMC) proliferation. However, the localized release of vildagliptin in the diabetic vessel damage has seldom been investigated. Research design and methods: In this work, nanofiber-eluting stents that loaded with vildagliptin, a dipeptidyl peptidase-4 enzyme (DPP-4) inhibitor, was fabricated to treat diabetic vascular disease. To prepare nanofibers, the poly (D,L)-lactide-co-glycolide (PLGA) and vildagliptin were mixed using hexafluoroisopropanol and electrospinning process. In vitro and in vivo release rates of the vildagliptin were characterized using high-performance liquid chromatography.

Results: Effective vildagliptin concentrations were delivered for more than 28 days from the nanofibrous membranes coating on the surface of the stents in vitro and in vivo. The vildagliptineluting PLGA membranes greatly accelerated the recovery of diabetic endothelia and reduced SMC hyperplasia. The type I collagen content of the diabetic vascular intimal area that was treated by vildagliptin-eluting stents was lower than that of the non-vildagliptin-eluting group. Conclusion: The experimental results revealed that stenting with vildagliptin-eluting PLGA membranes could potentially promote healing for diabetic arterial diseases.

Keywords: re-endothelialization, neointimal hyperplasia, vildagliptin, biodegradable drugeluting nanofibers

\section{Introduction}

Several million people globally suffer from diabetes mellitus, and the prevalence of this disease is rapidly increasing. ${ }^{1}$ Diabetes mellitus increases the likelihood of various vascular complications, including cerebrovascular, coronary, and peripheral arterial disease, by a factor of up to four, and it is a major risk element for cardiovascular morbidity and mortality. ${ }^{2,3}$ Abnormalities in endothelial cell (EC) and vascular smooth muscle cell (SMC) function, as well as a propensity to thrombosis, contribute to atherosclerosis and its complications. ${ }^{4}$ Endothelial dysfunction has an important role in the pathogenesis of diabetic vascular disease. By producing vasodilator mediators, the endothelium also influences the tone of the underlying SMCs. ${ }^{5-7}$ Moreover, diabetes promotes the migration of vascular SMCs into nascent intimal lesions, where they replicate and produce an extracellular matrix (ECM); this step is important in atherosclerotic lesion formation. ${ }^{8}$ Moreover, patients with diabetes tend to have higher SMCs apoptosis in lesions, increasing the propensity of instability to undergo
Correspondence: Shih-Jung Liu Biomaterials Lab, Department of Mechanical Engineering, Chang Gung University, 259, Wen-Hwa Ist Road, Kwei-Shan, Tao-Yuan 333, Taiwan

Tel +8863211 8166

Fax +886321I 8558

Email profsjliu5347@gmail.com 
plaque rupture. ${ }^{9,10}$ The use of limus-based or paclitaxel drugeluting stents (DESs) is the main treatment option for treating coronary arterial atherosclerosis. ${ }^{11,12}$ These drugs can significantly impair EC development following inadequate reendothelialization to generate a risk of stent restenosis. ${ }^{13}$ Therefore, an ideal DES should continually impede the hyperplasia of SMCs and accelerate re-endothelialization. ${ }^{14}$

Vildagliptin, a dipeptidyl peptidase-4 (DPP-4) inhibitor that prevents the degradation of glucagon-like peptide-1, is a glucose-dependent insulinotropic polypeptide that is extensively used to enhance endothelium-dependent vasodilatation in patients with diabetes. ${ }^{15,16}$ The anti-atherosclerotic effect of DPP-4 inhibitor involves its reduction of SMC hyperplasia and the inflammatory reaction. ${ }^{17}$

Poly(D,L)-lactide-co-glycolide (PLGA) is one of the non-cytotoxic and biodegradable synthesized copolymers that degrade without accumulating in the vital organs. ${ }^{18-20}$ PLGA degrades by hydrolysis in the presence of water. The time required for degradation of PLGA depends on the monomers' ratio used in production, ie, the higher the content of glycolide units, the shorter the degradation time as compared to predominantly lactide materials. An exception to this rule is the copolymer with 50:50 monomers' ratio which exhibits the faster degradation. Electrospinning is a unique method that can fabricate non-woven fibrous matrix with fiber diameters ranging from tens of nanometers to microns, a size range that is otherwise hard to develop by conventional non-woven fiber fabrication techniques. ${ }^{21,22}$ Electrospun nanofibrous scaffolds gives a remarkably high ratio of surface-to-volume, malleability to conform over a extended variety of shapes, sizes, and tunable porosity. ${ }^{23}$

We hypothesize that nanofibrous vildagliptin-eluting PLGA membranes may enhance endothelial recovery and inhibit the proliferation of SMCs in diabetic injured arteries. Local delivery of vildagliptin enables the transportation of high drug concentrations to treat the diabetic angiopathies and minimizes potential systemic side effects, such as nausea, hypoglycemia, tremor, headache and dizziness, as well as a rare but severe possible side effect of hepatoxicity. ${ }^{24}$ PLGA vildagliptin-eluting stents that release two different drug concentration locally to damaged diabetic vessel walls. The acceleration of EC proliferation and functional repair that are resulted from drug loading, and the prevention of neo-intimal proliferation are evaluated using treatment of the vildagliptineluting stents in injured blood vessel in a diabetic model.

\section{Research design and methods Vildagliptin-eluting stents}

The biodegradable polymer and solvent that were used herein were commercially available PLGA (lactide:glycolide ratio of 50:50; Resomer RG 503) and hexafluoroisopropanol (HFIP), respectively (Sigma-Aldrich, Saint Louis, MO, USA). Vildagliptin was obtained from Novartis Pharma AG.

After a few test trails for process optimization, the experimental design included a syringe with a blunt needle of $420 \mu \mathrm{m}$ in diameter and a metallic pin of $950 \mu \mathrm{m}$ in diameter fixed on a motor that rotated at a speed of 300 $\mathrm{rpm} .{ }^{25}$ An electrode from a high voltage power supply (35 $\mathrm{kV}$ and $4.16 \mathrm{~mA}$ ) was placed in contact with the needle and the metallic pin, and an electric field was applied. To electrospun three kinds of nanofibers, pure PLGA (280 $\mathrm{mg}$ ) and PLGA combined with vildagliptin (dose 1: 240 $\mathrm{mg} / 40 \mathrm{mg}$; dose 2: $260 \mathrm{mg} / 20 \mathrm{mg}$, w/w) were mixed with $1.0 \mathrm{~mL}$ HFIP. The electrospinning was then conducted on a feed pump (volume flow rate of $60 \mu \mathrm{L} / \mathrm{min}$ ) to yield nanofibrous capillary tubes on the soft polyethylene tubing (outside diameter: $1.52 \mathrm{~mm}$ ) (Clay Adams Brand, Benton, Dickson and Company, Sparks, MD, USA) mounted on metallic pin at room temperature. The distance between the needle tip and the ground electrode was $10 \mathrm{~cm}$, and a positive voltage of $17 \mathrm{kV}$ was applied to the polymer solutions. Electrospun nanofibrous membranes were mounted on Gazella bare-metal stents $(3.0 \times 14 \mathrm{~mm}$, Biosensors International, Morges, Switzerland). The vildagliptin combined with PLGA nanofiber-eluting stents were thus fabricated. All materials were retained in a vacuum drying oven at $40^{\circ} \mathrm{C}$ for 3 days for solvent removal.

\section{Nanofibrous densities}

The nanofibers densities were obtained by the following equation:

$$
\operatorname{Porocity}(\%)=\left\{1-\frac{\rho_{\text {membrane }}}{\rho_{\text {polymer }}}\right\} \times 100
$$

where $\rho_{\text {membrane }}$ and $\rho_{\text {polymer }}$ are the densities of the drugeluting nanofibrous membrane and the true PLGA polymer, respectively.

\section{Scanning electron microscope (SEM) observation}

The morphology of the nanofibers was detected using SEM (Hitachi S-3000N, Tokyo, Japan) and analyzed by 
Image $\mathrm{J}$ image software (National Institutes of Health, Bethesda, MD, USA).

\section{In vitro and in vivo elution}

To quantify the release patterns of vildagliptin, an in vitro elution method was used. The dissolution medium was a PBS. The membranes were put in a glass test tube with 3 $\mathrm{mL}$ of PBS at $37^{\circ} \mathrm{C}$. The dissolution medium was taken and changed with new PBS every $24 \mathrm{hrs}$ for 30 days. The drug that was eluted to the stented aorta in vivo, which was retrieved during animal sacrifice, was also characterized using HPLC after 8 weeks of implantation.

Using an HPLC assay, the concentrations of the buffer that were used in the elution studies and blood were both obtained. HPLC analyses were performed using a Hitachi L2400 UV-VIS System. An Agilent XDB C $18,4.6 \times 150 \mathrm{~mm}$ HPLC column was used for the separation. The absorbency at a $210 \mathrm{~nm}$ wavelength was monitored with $1.0 \mathrm{~mL} / \mathrm{min}$ flow rate. The mobile phase contained $0.1 \mathrm{M}$ phosphate buffer and acetonitrile (Mallinckrodt, USA) $(85 / 15, \mathrm{v} / \mathrm{v}){ }^{26}$

\section{Cell cultures for migration assay}

Human umbilical vein endothelial cells (HUVECs) were isolated with written and informed consent signed by donor. In brief, cells were grown in M199 medium that was supplemented with $16 \%$ fetal bovine serum and $20 \%$ EGM-2 (Clonetics, USA). Cells were passaged at confluence with $0.05 \%$ trypsin and maintained in a $37^{\circ} \mathrm{C}$ incubator with a humidified atmosphere of 5\% CO2 and 95\% air. All cells were passaged three to five times before being used in experiments. Transwell filters (Costar, Cambridge, MA, USA) with $8.0 \mu \mathrm{m}$ pores were used with seeding HUVECs $\left(6 \times 10^{4}\right.$ cells $)$ in the migration assay for in vitro eluents (day 14). All experimental procedures were approved by the Institutional Ethics Committee in Chang Gung University College of Medicine.

\section{Preparation of diabetic rabbit and implantation of hybrid stents}

Thirty adult male alloxan-induced-diabetic New Zealand white rabbits were included in the animal study and were institutionally approved by the Committee of the Chang Gung University (Approval Number CGU 106-037) and were cared for according to the regulations of the National Institute of Health of Taiwan under the supervision of a licensed veterinarian. Alloxan monohydrate $(120 \mathrm{mg} / \mathrm{kg})$ was injected intravenously through the marginal ear vein over a period of $120 \mathrm{~s}$ using a 25 gauge butterfly catheter to induce diabetes $^{27}$ (Sigma Aldrich Chemical, Saint Louis, MO, USA). After 14 days, the diabetic animals were confirmed based on their blood glucose levels ( $>300 \mathrm{mg} / \mathrm{dL})$. Blood was collected daily from the ear vein of each rabbit and the glucose level was tested by OneTouch strips (LifeScan, Milpitas, CA, USA). Insulin glargine (SanofiAventis, Frankfurt, Germany) was used if the animals were found with weight loss or "high" glucose readings.

Animals were well anesthetized and sedated using xylazine and Zoletil $50^{\mathrm{TM}}{ }^{28}$ Using the puncture technique, a sheath $(5 \mathrm{~F})$ was placed in the femoral artery temporarily. Thirty animals were separated into three groups. Group A comprised ten animals implanted with a high vildagliptin dose loading stents; group B included ten animals in which stents were implanted with a low vildagliptin dose loading; group $\mathrm{C}$ included ten rabbits in which were implanted stents using pure PLGA without loading drug. Since the evidence of more extensive micro-damage will be present after 5 months duration of diabetes, ${ }^{29}$ to accelerate the process, the ECs of the descending abdominal aorta were also denudated via a $3.0 \times 20 \mathrm{~mm}$ balloon to induce a significant vascular injury. Stents were then implanted in the abdominal aorta (lower part). ${ }^{30}$ While the stents had reached the low descending abdominal aorta sites, they were inflated to a diameter of $3.0 \mathrm{~mm}$ for $15 \mathrm{~s}$ under 8 bars. Post-procedural angiography was performed to check vessel patency and position verification before the animals were allowed to recover. All rabbits were treated with $40 \mathrm{mg}$ aspirin orally per day.

After stent deployment, written records were maintained for daily body weight variation, fluid and food consumption, any behavioral or clinical changes, and hydration status. The iE33 ultrasound device (Philips Medical Systems, WA, USA) was used to evaluate the patency of the arteries for early (0-30 days post stent implantation) and late ( $>30$ days) stent thrombosis at the days 30 and 56, respectively.

\section{In vivo evaluation of endothelial function}

Using the marginal ear vein, on day 21, the infusions of two increasing concentrations of acetylcholine (Ach, 0.5 and $0.05 \mu \mathrm{g} / \mathrm{mL} / \mathrm{min}$ ) were used to evaluate endotheliumdependent vasomotor response near non-stented reference segments. $^{31}$

After 2 months, stented vessels, including those that had been implanted with vildagliptin-eluting stents (group A: high dose; group B: low dose) and non-vildagliptin-eluting stents (group C: pure PLGA) were examined for the inflammatory and injury outcomes. For analyzing their immunofluorescence, 
the areas that were near to both the vildagliptin-eluting and non-vildagliptin-eluting stented regions were cut transversely.

\section{Microscopic observation}

Whole stenting arteries were longitudinally bisected for evaluating re-endothelialization of the lumen surface using an SEM $(\times 35$ and $\times 200)$. The coverage of the ECs was also quantified. ${ }^{32}$

\section{Histology}

Two histopathological approaches of scoring vascular injury and inflammation were carried out. ${ }^{33,34}$ The inflammation score took into consideration the extent and density of the inflammatory infiltrate, including mononuclear and foreign-body giant cells in each individual strut. The scores were calculated to yield the average values for 90 histological regions of the 30 stented sites at 56 days.

\section{Immunofluorescence}

The reagents and fluorescent dyes were acquired from Sigma (St. Louis, MO, USA) and Molecular Probes Inc. (Eugene, OR, USA), respectively. The sections were treated with primary antibodies against type I collagen, followed by Cy3-conjugated secondary antibody (Chemicon, Temecula, CA, USA).

\section{Western blot analysis}

The protein $(30 \mu \mathrm{g})$ prepared from blood vessels close to the stent was tested using the primary anti-collagen I antibody (ab90395) (Abcam Biotechnology, USA). The protein content was presented as the ratio to the glyceraldehyde-3-phosphate dehydrogenaseamount.

\section{Data analysis and statistics}

Data were shown as mean \pm standard deviation. One-way ANOVA was employed to find statistically different results among three groups. The post hoc Bonferroni method for multiple comparisons was performed to identify significant differences between groups. If $p<0.05$, differences were statistically significant. The relevant data were performed by SPSS software (version 17.0 for Windows; SPSS Inc, Chicago, IL, USA).

\section{Results}

\section{In vitro assessment of stent/ biodegradable nanofibers}

Stents that were loaded with nanofibers with two vildagliptin doses were successfully developed by the electrospinning procedure. Figure 1 displays SEM photos $(2000 \times)$ of nanofibrous membranes with a high dose (Figure 1A) and a low dose of vildagliptin (Figure 1B). A significant difference between the diameters was observed in the electrospun PLGAs with the two concentrations of vildagliptin (group A: $1152.9 \pm 448.8 \mathrm{~nm}$ vs group B: $365.0 \pm 135.7 ; p<0.001$ ) (Figure 1C and D). Moreover, the pore size in group A was considerably larger than in group $B\left(187.6 \pm 89.6 \times 10^{5} \mathrm{~nm}^{2}\right.$ for group A and $42.1 \pm 25.9 \times 10^{5} \mathrm{~nm}^{2}$ for group B) $(p<0.001)$. The porosity of the nanofibrous membranes in these two groups was high $(84.3 \pm 1.2 \%$ and $82.2 \pm 2.2 \%$ in the vildagliptineluting PLGA Group A and B nanofibers, respectively) $(p>0.05)$.

The in vitro release characteristic of stents that were loaded with vildagliptin-eluting biodegradable nanofibers was quantified for 28 days. Figure 1 also schemes the daily
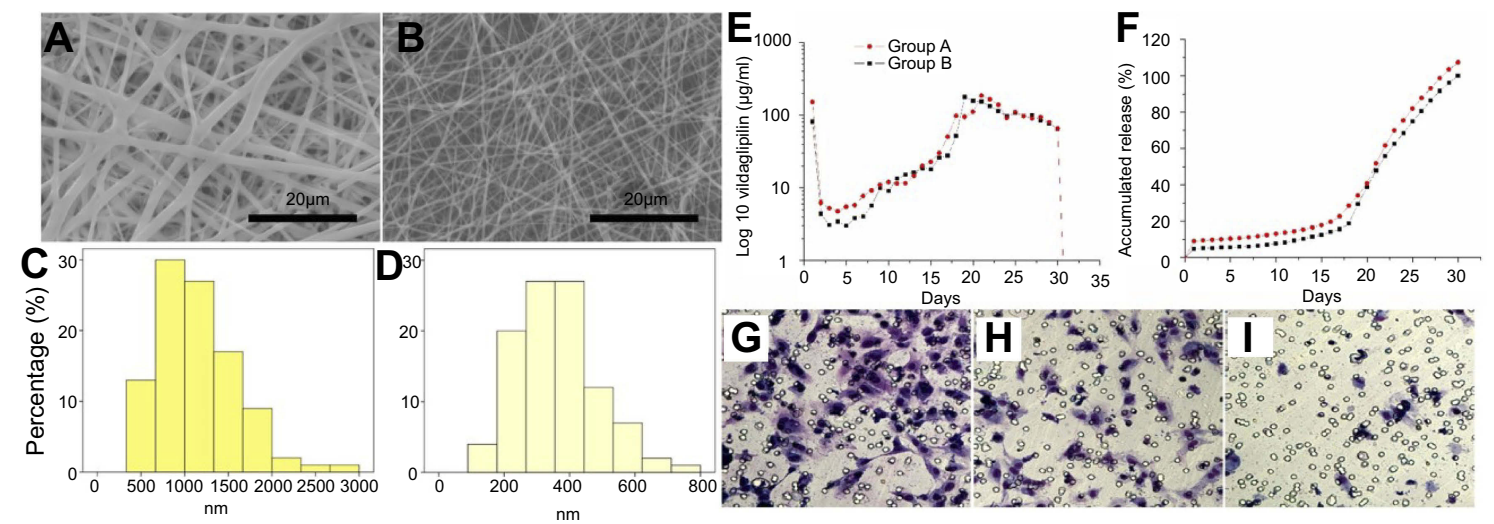

Figure I Morphology of high (A) and low (B) vildagliptin-eluting nanofibers, examined by scanning electron microscopy (SEM) with a magnification of 2000x. The measured mean diameters of nanofiber were $1152.9 \pm 448.8 \mathrm{~nm}(\mathbf{C})$ in group $A$ and $365.0 \pm 135.7 \mathrm{~nm}(\mathbf{D})$ in group B $(p<0.00 \mathrm{I})$. (Scale bar: $20 \mu \mathrm{m})(\mathbf{E})$ Daily and $(\mathbf{F})$ accumulated delivery of vildagliptin from nanofibrous tubes in vitro. In vitro: transwell filter migration assay. Remarkable effect of dose on migration of ECs was noted. Ratios of migration of ECs treated with high- $(\mathbf{G})$ and low- $(\mathbf{H})$ dose vildagliptin eluents (day 14) to that on the control group (I) were $224 \pm 33 \%$ and I6I $\pm 34 \%$, respectively. 
(Figure 1E) and accumulated (Figure 1F) release curves of vildagliptin-eluting nanofibrous tubes. The results suggested that the hybrid stents had triphasic drug distribution characteristics with an early burst delivery on first day (151.9 \pm 3.5 (group A) and $81 \pm 1.7$ (group B) $\mu \mathrm{g} / \mathrm{mL}$ ), and a second highest release concentration on days 19-21 (185 \pm 1.4 (group A) and $177 \pm 0.5$ (group B) $\mu \mathrm{g} / \mathrm{mL}$ ), following by a relatively steady delivery of vildagliptin until day 28 . The in vivo drug concentrations of vildagliptin close to the stented vessels after 8 weeks were measured to be 82.0 \pm 2.6 (group A) and $66.7 \pm 5.2$ (group B) $\mu \mathrm{g} / \mathrm{mL}$. In this study, PLGA with lactide:glycolide (LA:GA) ratio of 50:50 was employed as the drug delivery vehicle. PLGAs of different LA:GA ratios or molecular weights may also be used to regulate the timing and steerability of nanofibers.

Statistically significant cell migrations using the transwell filter were observed in vildagliptin elutes-treated ECs. Figure $1 \mathrm{G}-\mathrm{I}$ reveals that vildagliptin eluents (day 14) yielded significantly higher EC migration (Figure $1 \mathrm{G}$ (high dose group) and $1 \mathrm{hr}$ (low dose group)) than those without eluents (Figure 3C). The migration in ECs that were treated with high- (g) and low- (h) dose vildagliptin eluents was $224 \pm 33 \%$ and $161 \pm 34 \%$, respectively, that related to control group (i).

\section{In vivo}

In vivo investigations were carried out using 30 implanted stents (the femoral puncture successful rate was 30/ $36=83 \%$; six rabbits had puncture failure due to small vessels) (Figure 2A) that were loaded with and without vildagliptin-eluting biodegradable nanofibers in the descending aorta (Figure 2B and C) of rabbits. Vessel position and stent deployment were verified by angiography from femoral artery (Figure 2B, asterisk).

Figure 3 shows the observed re-endothelialization on the damaged arterial walls. After 2 months, endothelial coverage on the surfaces of struts among the groups showed that reendothelialization was remarkably superior in group A (98.4 $\pm 1.0 \%)$ and group B $(95.4 \pm 1.1 \%)$ to those in control group C $(90.0 \pm 1.6 \%)$ (all post hoc $p<0.001)$. No cases or any signs of in-stent thrombosis were noticed during these 2 months.

The surfaces of the struts herein were almost fully covered with regularly shaped endothelia in close contact with each other (Figure 3A and B). However, poor alignment and extended irregular intercellular spaces were identified in group C (Figure 3C). Remarkable re-endothelialization was thus obtained when nanofibrous stents with various doses of vildagliptin were used (Figure 3D-F).

Each endothelial response was carried out following 3 weeks of stent procedure. The endothelia-dependent vasodilation in reaction to Ach was considerably better in the vildagliptin-eluting stents than in the non-vildagliptin-eluting stents (all $p<0.05$ ). Group $\mathrm{A}$, with a high vildagliptin loading, exhibited a similar vasodilatory response to that of group B ( $p$-value $=0.361$ in Ach $0.05 \mu \mathrm{g} / \mathrm{mL} / \mathrm{min}$ and $p$ value $=0.177$ in Ach $0.5 \mu \mathrm{g} / \mathrm{mL} / \mathrm{min}$ ) (Figure $3 \mathrm{G}$ ).

\section{Histological examination}

Figure $4 \mathrm{~A}-\mathrm{C}$ shows the pathological pictures in the three groups that were stained by hematoxylin-eosin at 8 weeks. The degradable nanofibrous membranes coated outside of implanted stents were noticed between dotted line and double arrow. The thickness of residual PLGA at day 56

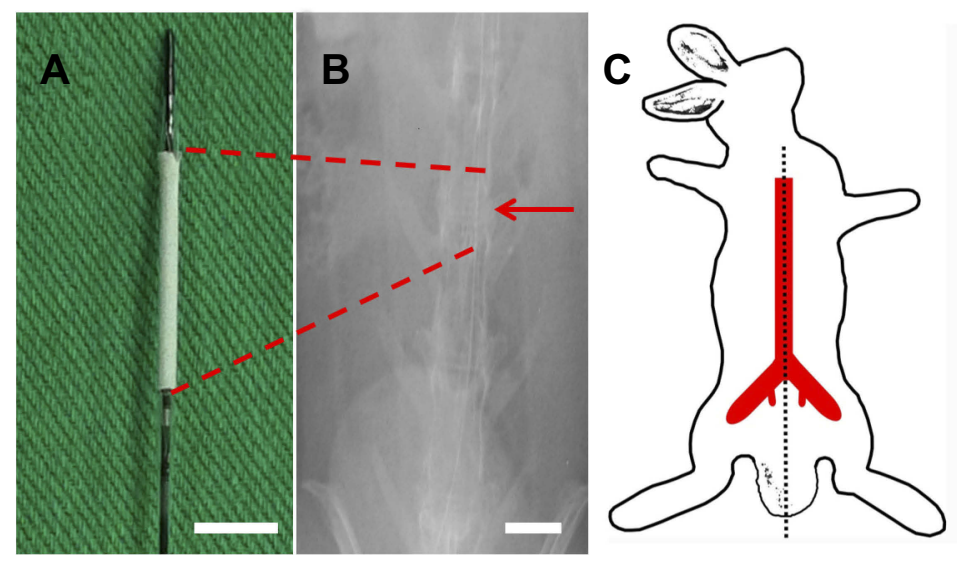

Figure 2 Stent and angiograms in rabbit descending aorta. (A) Photograph of vildagliptin-eluting stent. The nanofibrous tube was made on a bare-metal stent. (Scale bar: 5 $\mathrm{mm}$ ) (B) Angiograms of rabbit vasculature in area of stent implantation (red arrow head) (scale bar: 10 mm) following injection of contrast dye from femoral artery (red asterisk). (C) Locations of rabbit vasculature. 

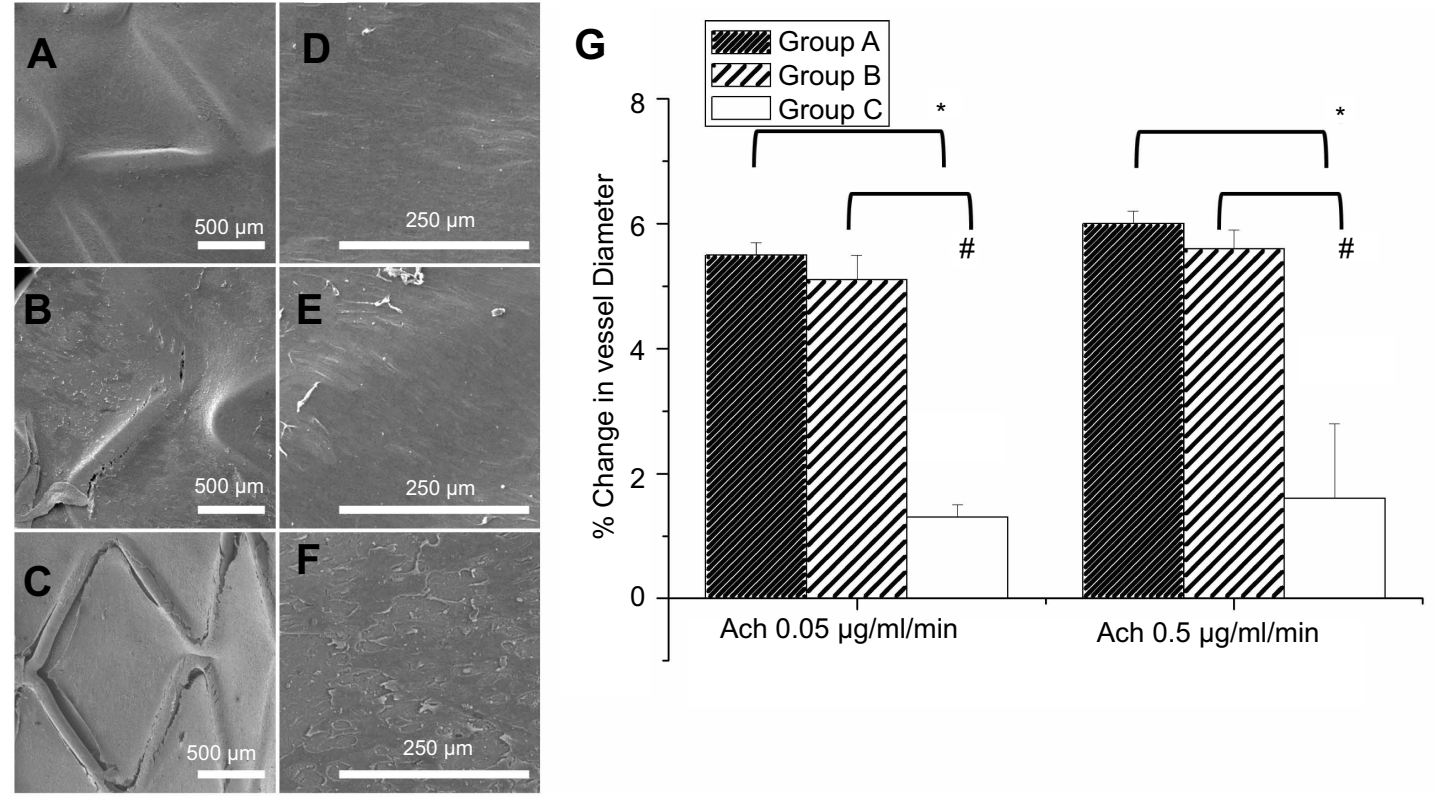

Figure 3 Evaluation of the coverage and morphology of endothelium and in vivo endothelial function after 3 weeks of stenting treatment was evaluated from variation in abdominal aorta diameter using different acetylcholine dose infusions. The coverage of endothelium on struts in three groups at 8 weeks at different magnifications ( $35 \times$ : a, b, and c with scale bar: $500 \mu \mathrm{m} ; 200 \times$ : d, e, and f with scale bar: $250 \mu \mathrm{m}$ ). (A) Group A had full coverage. (B) Almost full coverage was noted on stent struts in group B. (C) The region in which stents were deployed was poorly covered in group $C$. ( $D$ and $\mathbf{E}$ ) Endothelial cells in groups $A$ and $B$ were aligned parallel to the flow direction with regularly shaped endothelial cells among each other by close contact. $(\mathbf{F})$ Endothelial alignment of stenting vessels in group B was more weakly in flow direction. Extended and uneven intercellular spaces, irregular size of endothelial cells, and poorly aligned surface were shown in group $C$. (G) Significantly greater responses in vildagliptin-eluting stent than that in non-drug-eluting stent were observed according to endothelial-dependent vasodilatory reaction to Ach. $\left({ }^{*} p<0.05\right.$ group $A$ versus group $C$; \# $p<0.05$ group $B$ versus group $C$ ).

decreased significantly in group A $(15.6 \pm 2.5 \mu \mathrm{m})$ comparing with those in group B $(54.1 \pm 20.1 \mu \mathrm{m})(p=0.001)$ and group C $(74.2 \pm 12.9 \mu \mathrm{m})(p<0.001)$. By 8 weeks, most endothelium was anatomically repaired, and no remarkably intimal proliferation was observed in group A or B. However, intimal hyperplasia (around $200 \mu \mathrm{m}$ ) was observed in group C. In vivo inflammation responses were negligible in all three groups (asterisk area).

The vascular injury and inflammation scores within stent struts were also evaluated. At 8 weeks, all rabbits exhibited comparable vascular injury responses (group A: $0.52 \pm 0.07$, group B: $0.51 \pm 0.08$, and group C: $0.53 \pm 0.10$ ) and similar vascular inflammatory responses (group A (0.52 \pm 0.20$)$, group B $(0.53 \pm 0.17)$, group C $(0.53 \pm 0.22))$ (all ANOVA $p>0.05$ ).

\section{Collagen type I on 8 weeks following response of balloon injury to diabetic vessel} Using the confocal fluorescence microscopy, immunofluorescent labeling with type I collagen was conducted around stented regions (Figure 4: a1 to $\mathrm{c} 1$ and a2 to $\mathrm{c} 2$ ). The cell nuclei were co-stained with DAPI (Figure 4 a3 to c3). In the interstitial of intima and elastic lamina of the aorta, the collagen labeling index (collagen/DAPI-labeled nuclei) was evaluated. Lower collagen I content was noted around the vildagliptin-eluting stented areas (group A: $0.53 \pm 0.02$; group B: $0.80 \pm 0.10$ ) than was noted near the non-vildagliptin-eluting stented areas (group C: 0.94 \pm 0.06 ) (all $p<0.05$ ). Furthermore, significant neointima hyperplasia caused by the accumulation of SMCs, resulting in intima as well as media was observed in group $\mathrm{C}$ (Figure 4C double arrow).

\section{Local expression of collagen I from Western blotting}

Eight weeks following implantation of stents, the vildagliptin-eluting stent exhibited protection of the ECs by reducing the local appearance of collagen $I$ in the stenting region. Figure 5 presents the stents that were loaded with either a high or a low dose of vildagliptin exhibited less local expression of collagen I than did the non-eluting stents in the control group ( $p$-value all $<0.001)$.

\section{Discussion}

Vildagliptin-eluting biodegradable PLGA nanofibers with two drug concentration were fabricated using electrospinning. The hybrid stent composed with vildagliptin/PLGA 


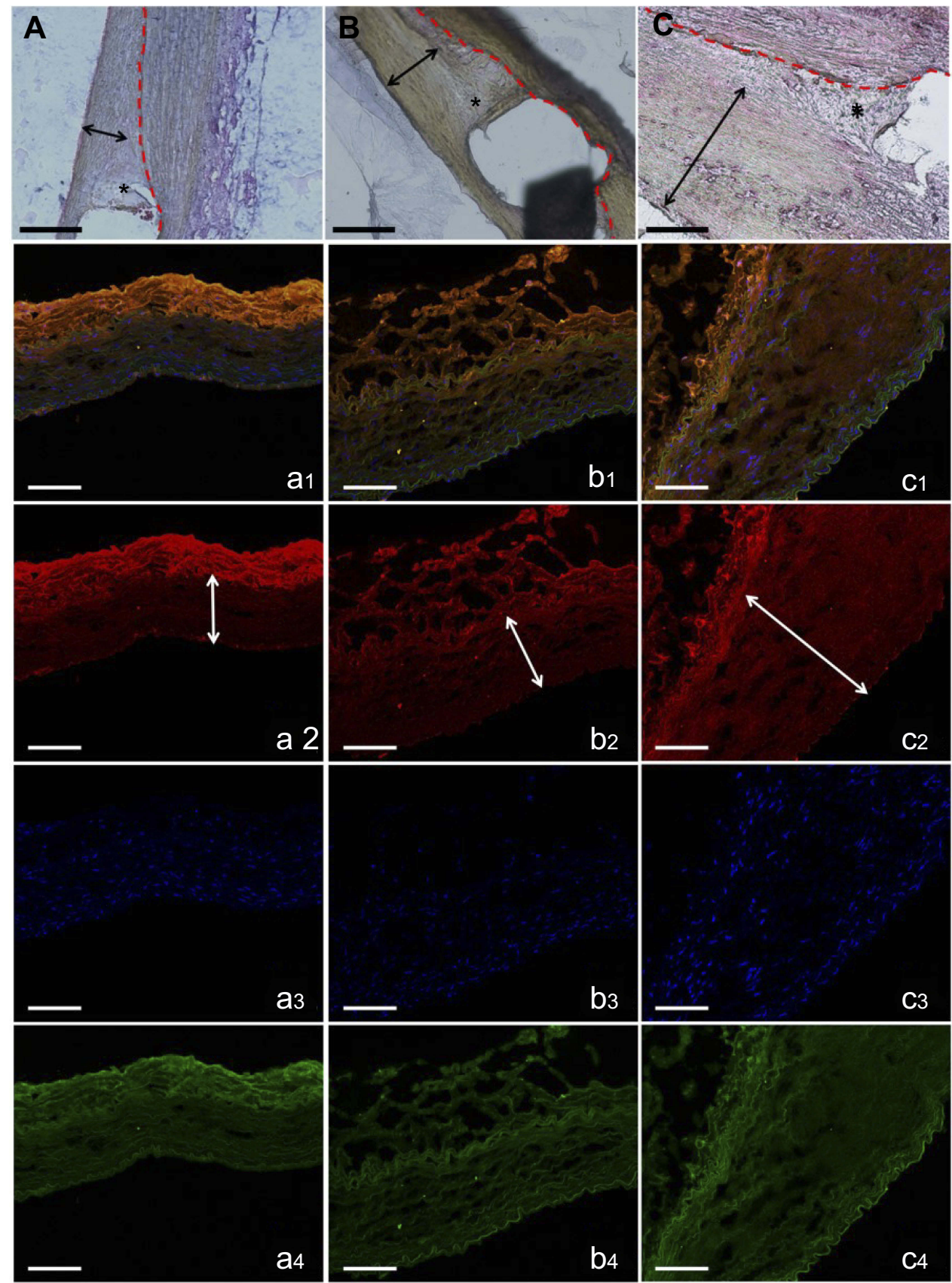

Figure $4 \mathrm{H} \& \mathrm{E}$ staining of vessel sections after eight weeks $(\times 200)$. The degradable nanofibrous membranes coated outside of implanted stents were noticed between dotted line and double arrow. Inflammation response was small around stent struts in all groups (asterisk). Groups A (A) and B (B) exhibited almost no neointimal formation, but group C (C) revealed significant neointimal formation with nearly $200 \mu \mathrm{m}$ thickness (scale bar: $100 \mu \mathrm{m}$ ). Immunofluorescence of type I collagen. Type I collagen (orange) of vildagliptin-eluting (a: high dose and b: low dose) and non-vildagliptin-eluting nanofibrous membrane stent (C). DAPI stained nuclei (blue) and autofluorescence on tunica media (green) are also displayed, respectively. Lower labeling level with collagen type I was detected near drug-eluting stented vessels. Double arrow indicates elastic lamina. Marked neointima hyperplasia owing to the growth of smooth muscle cells in media leads to expression of intima and media regions in group $\mathrm{C}$ (c2, double arrow) (scale bar: $100 \mu \mathrm{m})$.

nanofiber loading in vitro and in vivo showed sustained and local release of adequate concentrations drug level. The improvement of sustained and prolong release of vildagliptin leads to the retention of the critical protective benefit of the endothelial recovery and decrease of SMC proliferation.
Morphological characteristics and diameters of nanofibers are the factors that dominate the physical properties of fibrous scaffolds. ${ }^{35,36}$ To transport metabolic wastes and nutrients, the attachment of ECs to surfaces must be optimized for proliferation and penetration. Furthermore, pore sizes of less than the cell 


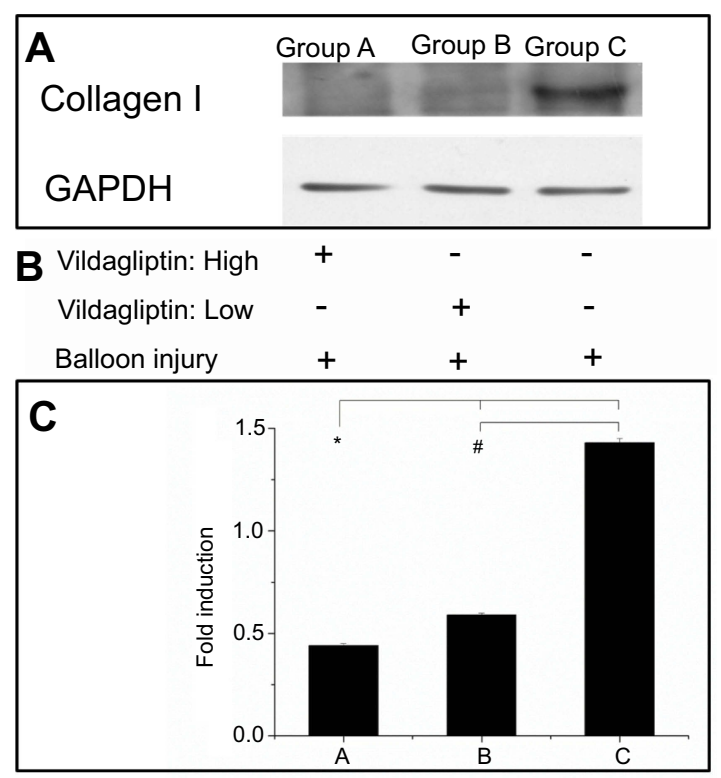

Figure 5 Western blot of collagen I content (A). After balloon injury, various groups with stents loaded and not loaded with vildagliptin-eluting nanofibers, or without stents (B). Relative expression of each protein was quantified by densitometry as a ratio of density to that of corresponding GAPDH (C). Each value is presented as mean $\pm \mathrm{SE}$. $\left({ }^{*} \#<<0.001\right.$ group $A$ or $B$ versus group $C$ in post hoc analysis.

diameter may prevent cell penetration. ${ }^{37}$ The fabricated vildagliptin-eluting nanofibrous membranes in this investigation have pores that enable the penetration and proliferation of the spherical ECs capable and so serve as an effective and practical scaffold for tissue engineering applications.

Drug release kinetics for biodegradable drug-eluting nanofibers generally comprise three stages $^{38}$ - an early burst, diffusion-limited release, and a degradation-controlled stage. In the fabrication procedure, utmost pharmaceuticals are encapsulated and distributed in the PLGA membranes. Certain drug compounds, however, may be left behind on the membrane surface and cause the early burst. Following the burst release, diffusion and polymer degradation dominate the drug-elution profile. A relatively constant and steady elution of vildagliptin thus occurs. Nanofibers with a low drug dose exhibit a slower drug release characteristic. In a drug delivery scaffold, the drug loading has importantly affected the duration and rate of drug release. Scaffolds that are loaded with a low drug dose generally have a smaller initial burst release than those delivered with a higher drug concentration, mainly because of their higher polymer-to-drug ratio. ${ }^{39}$ Experimental results demonstrated that the hybrid DESs that are fabricated in this study can provide the sustained and local release of adequate doses of vildagliptin for 28 days in vitro and 8 weeks in vivo.
Re-endothelialization generally occurs soon after stent deployment, but a newly regenerated endothelial layer is generally dysfunctional. ${ }^{40}$ The treatment of diabetic patients with DPP-4 inhibitor can reverse vascular endothelial dysfunction by promoting flow-mediated dilation and causing pleiotropic effects that modulate cardiovascular disorders. ${ }^{41}$ The critical time course of arterial healing, involving re-endothelialization after vascular injury-induced partially or completely denude, ${ }^{42}$ was observed at 14 days. Remarkable ECs migration on day 14 with effective levels of vildagliptin may improve the endothelial recovery of denuded vessels. The increased migration of ECs on day 14 herein may be caused by the fact that the effective drug release levels on day 14 are higher than those on day 7, supporting that the recovery of functional ECs having vascular tone and permeability to manage the exchange of molecules in response to physical and chemical signals. ${ }^{43}$

To study the effects of transluminal angioplasty, the rabbit vascular injury model is developed to simulate human disease. ${ }^{44}$ The puncture technique for establishing a route for inserting a stent may be more effective and cause less damage to the animals than the method of isolation of femoral artery by a short incision in the groin area.

The vascular endothelial dysfunction is a marker of the early stage of atherosclerosis and vascular complications in diabetic patients. ${ }^{16}$ Drugs that are released from a vildagliptin-eluting stent can accelerate endothelial regeneration after endothelial injury.

In response to the neurohumoral substances and/or external mechanical stimuli, ECs can send out messages the underlying smooth muscle to cause it to contract and relax, setting its tone. DPP-4 inhibitors exhibit direct endothelium-dependent vasorelaxation and have an effect on antioxidant that improves endothelial function. ${ }^{45,46}$ Since systemic DPP-4 inhibitor treatment has been demonstrated effectively to improve endothelial function, the local and slow delivery of vildagliptin by DES in an injured diabetic vessel may be an effective and alternative treatment for endothelial dysfunction in diabetes.

The foreign-body response of implanted biomaterials, which limits their use in advanced therapies, which may involve cardiovascular implants and tissue engineering scaffolds, has raised concerns. ${ }^{47}$ Related experimental results indicated that the reactions between tissue and a vildagliptin-eluting stent are mild, demonstrating the safety of PLGA as a material for drug delivery and 
vascular regeneration. Meanwhile, intimal hyperplasia causes a major problem with respect to patency after stent implantation. In atherogenic mice, DPP-4 inhibitor appears to suppress neointimal formation beyond its effects on cholesterol and glucose metabolism. ${ }^{48,49}$ Experiments in the present work have revealed that vildagliptin-eluting stents effectively inhibit intimal neointimal formation in injured vessels in animals with diabetes.

The effects of vildagliptin are associated with its reducing vascular stiffening, anti-inflammatory potential, and intimal hyperplasia by its reducing collagen expression. $^{50,51}$ The accumulation of ECM components within the arterial wall and the proliferation of vascular SMCs resulted from local injury are the main causes in vascular proliferative problems, such as restenosis and arteriosclerosis following angioplasty. ${ }^{52}$ The downregulation of collagen I by vildagliptin may contribute to the pleiotropical improvement of endothelial functions and reduce intimal hyperplasia.

\section{Limitations of the study}

Despite its important contributions, this study has some limitations. The effects of the sustained vildagliptin via hybrid nanofibers and stents without chronic diabetic arteries may have underestimated the influence of structural changes in the endothelial lining on the arterial vasculature and high predilection to atherosclerosis in diabetes. Drug-induced diabetic animal models that are used in this study in the evaluation of vildagliptin-eluted stents are also limited in their ability to replicate human atherosclerotic arteries. Future works should analyze atherosclerotic coronary models to verify further the analytical results in this work.

\section{Conclusion}

The developed hybrid stent/biodegradable vildagliptineluting nanofibers prevent neointimal hyperplasia and favor re-endothelialization in damaged diabetic vessels. Vildagliptin-eluting nanofibrous membranes were biologically useful and greatly powerful promoters of the migration of ECs. These stent/biodegradable drug-eluting nanofibers provide the sustainable and local release of vildagliptin. Stents with highly vildagliptin-eluting nanofibers, which effectively reduce the proliferation of SMCs and enhance endothelial recovery, may offer treat insights into diabetic patients at a high lifetime risk of vascular disease.

\section{Acknowledgments}

The authors would like to thank the Ministry of Science and Technology, Taiwan (Contract No. NSC-105-2314-B182A-098-MY2 and MOST-108-2221-E-182-004) and Chang Gung Memorial Hospital (Contract No. CMRPG3G1291) for financially supporting this research.

\section{Disclosure}

The authors report no conflicts of interest with respect to this work.

\section{References}

1. Wild S, Roglic G, Green A, Sicree R, King H. Global prevalence of diabetes: estimates for the year 2000 and projections for 2030. Diabetes Care. 2004;27(5):1047-1053. doi:10.2337/diacare.27.5.1047

2. The Diabetes Control and Complications Trial Research Group. The effect of intensive treatment of diabetes on the development and progression of long-term complications in insulin-dependent diabetes mellitus. $N$ Engl J Med. 1993;329(14):977-986. doi:10.1056/ NEJM199309303291401

3. Beckman JA, Creager MA, Libby P. Diabetes and atherosclerosis: epidemiology, pathophysiology, and management. JAMA. 2002;287 (19):2570-2581. doi:10.1001/jama.287.19.2570

4. Creager MA, Luscher TF, Cosentino F, Beckman JA. Diabetes and vascular disease: pathophysiology, clinical consequences, and medical therapy: part I. Circulation. 2003;108(12):1527-1532. doi:10.1161/01. CIR.0000091257.27563.32

5. De Vriese AS, Verbeuren TJ, Van de Voorde J, Lameire NH, Vanhoutte PM. Endothelial dysfunction in diabetes. Br J Pharmacol. 2000;130 (5):963-974. doi:10.1038/sj.bjp.0703393

6. Tesfamariam B, Brown ML, Deykin D, Cohen RA. Elevated glucose promotes generation of endothelium-derived vasoconstrictor prostanoids in rabbit aorta. J Clin Invest. 1990;85(3):929-932. doi:10.1172/ JCI114521

7. Ceriello A, Novials A, Ortega E, et al. Evidence that hyperglycemia after recovery from hypoglycemia worsens endothelial function and increases oxidative stress and inflammation in healthy control subjects and subjects with type 1 diabetes. Diabetes. 2012;61(11):29932997. doi:10.2337/db12-0224

8. Suzuki LA, Poot M, Gerrity RG, Bornfeldt KE. Diabetes accelerates smooth muscle accumulation in lesions of atherosclerosis: lack of direct growth-promoting effects of high glucose levels. Diabetes. 2001;50(4):851-860. doi:10.2337/diabetes.50.4.851

9. Makino A, Nakamura T, Hirano M, et al. High plasma levels of macrophage migration inhibitory factor are associated with adverse long-term outcome in patients with stable coronary artery disease and impaired glucose tolerance or type 2 diabetes mellitus. Atherosclerosis. 2010;213 (2):573-578. doi:10.1016/j.atherosclerosis.2010.09.004

10. Marfella R, Di Filippo C, Baldi A, et al. The vascular smooth muscle cells apoptosis in asymptomatic diabetic carotid plaques: role of glycemic control. J Am Coll Cardiol. 2006;47(10):2118-2120. doi:10.1016/j.jacc.2006.02.025

11. Morice MC, Serruys PW, Barragan P, et al. Long-term clinical outcomes with sirolimus-eluting coronary stents: five-year results of the RAVEL trial. J Am Coll Cardiol. 2007;50(14):1299-1304. doi:10.1016/j. jacc.2007.06.029

12. Silber S, Colombo A, Banning AP, et al. Final 5-year results of the TAXUS II trial: a randomized study to assess the effectiveness of slow- and moderate-release polymer-based paclitaxel-eluting stents for de novo coronary artery lesions. Circulation. 2009;120(15):14981504. doi:10.1161/CIRCULATIONAHA.109.849877 
13. Losordo DW, Isner JM, Diaz-Sandoval LJ. Endothelial recovery: the next target in restenosis prevention. Circulation. 2003;107(21):26352637. doi:10.1161/01.CIR.0000071083.31270.C3

14. Kipshidze N, Dangas G, Tsapenko M, et al. Role of the endothelium in modulating neointimal formation: vasculoprotective approaches to attenuate restenosis after percutaneous coronary interventions. $\mathrm{J} \mathrm{Am}$ Coll Cardiol. 2004;44(4):733-739. doi:10.1016/j.jacc.2004.04.048

15. Kalra S, Unnikrishnan AG, Agrawal N, Singh AK. Linagliptin and newer DPP-4 inhibitors: newer uses and newer indications. Recent Pat Endocr Metab Immune Drug Discov. 2011;5(3):197-202.

16. van Poppel PC, Netea MG, Smits P, Tack CJ. Vildagliptin improves endothelium-dependent vasodilatation in type 2 diabetes. Diabetes Care. 2011;34(9):2072-2077. doi:10.2337/dc10-2421

17. Ervinna N, Mita T, Yasunari E, et al. Anagliptin, a DPP-4 inhibitor, suppresses proliferation of vascular smooth muscles and monocyte inflammatory reaction and attenuates atherosclerosis in male apo Edeficient mice. Endocrinology. 2013;154(3):1260-1270. doi:10.1210/ en.2012-1855

18. Duan G, Fang H, Huang C, Jiang S, Hou H. Microstructures and mechanical properties of aligned electrospun carbon nanofibers from binary composites of polyacrylonitrile and polyamic acid. J Mater Sci. 2018;53(21):15096-15106. doi:10.1007/s10853-018-2700-y

19. Guo M, Bi S, Liu J, et al. C60 (OH) n-loaded nanofibrous membranes protect HaCaT cells from ROS-associated damage. Chin Chem Lett. 2017;28(9):1889-1892. doi:10.1016/j.cclet.2017.07.021

20. Jiang S, Han D, Huang C, Duan G, Hou H. Temperature-induced molecular orientation and mechanical properties of single electrospun polyimide nanofiber. Mater Lett. 2018;216:81-83. doi:10.1016/j. matlet.2017.12.146

21. Duan G, Greiner A. Air-blowing-assisted coaxial electrospinning toward high productivity of core/sheath and hollow fibers. Macromolecular Materials and Engineering. 2019;304:1800669.

22. Gao S, Tang G, Hua D, et al. Stimuli-responsive bio-based polymeric systems and their applications. J Mater Chem B. 2019;7(5):709-729. doi:10.1039/C8TB02491J

23. Lv D, Wang R, Tang G, et al. Eco-friendly electrospun membranes loaded with visible-light response nano-particles for multifunctional usages: high-efficient air filtration, dye scavenger and bactericide. ACS Appl Mater Interfaces. 2019. doi:10.1021/ acsami.9b01508

24. Bosi E, Camisasca RP, Collober C, Rochotte E, Garber AJ. Effects of vildagliptin on glucose control over 24 weeks in patients with type 2 diabetes inadequately controlled with metformin. Diabetes Care. 2007;30(4):890-895. doi:10.2337/dc06-1732

25. Teo WE, Ramakrishna S. A review on electrospinning design and nanofibre assemblies. Nanotechnology. 2006;17(14):R89-R106. doi:10.1088/0957-4484/17/14/R01

26. Boovizhikannan T, Palanirajan VK. RP-HPLC determination of vildagliptin in pure and in tablet formulation. J Pharm Res. 2013;7 (1):113-116. doi:10.1016/j.jopr.2013.01.001

27. Wang J, Wan R, Mo Y, Zhang Q, Sherwood LC, Chien S. Creating a long-term diabetic rabbit model. Exp Diabetes Res. 2010;2010:289614. doi:10.1155/2010/289614

28. Lee $\mathrm{CH}$, Chang SH, Lin YH, et al. Acceleration of re-endothelialization and inhibition of neointimal formation using hybrid biodegradable nanofibrous rosuvastatin-loaded stents. Biomaterials. 2014;35 (15):4417-4427. doi:10.1016/j.biomaterials.2014.02.017

29. Dolgov V, Zaikina O, Bondarenko M, Repin V. Aortic endothelium of alloxan diabetic rabbits: a quantitative study using scanning electron microscopy. Diabetologia. 1982;22(5):338-343.

30. Lee $\mathrm{CH}$, Lin $\mathrm{YH}$, Chang $\mathrm{SH}$, et al. Local sustained delivery of acetylsalicylic acid via hybrid stent with biodegradable nanofibers reduces adhesion of blood cells and promotes reendothelialization of the denuded artery. Int $J$ Nanomedicine. 2014;9:311-326. doi:10.2147/IJN.S51258
31. Drolet MC, Plante E, Battistini B, Couet J, Arsenault M. Early endothelial dysfunction in cholesterol-fed rabbits: a non-invasive in vivo ultrasound study. Cardiovasc Ultrasound. 2004;2:10. doi:10.1186/1476-7120-2-10

32. Nakazawa G, Granada JF, Alviar CL, et al. Anti-CD34 antibodies immobilized on the surface of sirolimus-eluting stents enhance stent endothelialization. JACC Cardiovasc Interv. 2010;3(1):68-75. doi:10.1016/j. jcin.2009.09.015

33. Kornowski R, Hong MK, Tio FO, Bramwell O, Wu H, Leon MB. Instent restenosis: contributions of inflammatory responses and arterial injury to neointimal hyperplasia. J Am Coll Cardiol. 1998;31(1):224230. doi:10.1016/s0735-1097(97)00450-6

34. Schwartz RS, Huber KC, Murphy JG, et al. Restenosis and the proportional neointimal response to coronary artery injury: results in a porcine model. J Am Coll Cardiol. 1992;19(2):267-274. doi:10.1016/0735-1097 (92)90476-4

35. Ko Y-G, Park JH, Lee JB, et al. Growth behavior of endothelial cells according to electrospun poly(D,L-lactic-co-glycolic acid) fiber diameter as a tissue engineering scaffold. Tissue Eng Regen Med. 2016;13(4):343-351. doi:10.1007/s13770-016-0053-7

36. Hassiba AJ, El Zowalaty ME, Nasrallah GK, et al. Review of recent research on biomedical applications of electrospun polymer nanofibers for improved wound healing. Nanomedicine (Lond). 2016;11 (6):715-737. doi:10.2217/nnm.15.211

37. Evers H, Birngruber CG, Ramsthaler F, Muller U, Bruck S, Verhoff MA. Differentiation of epithelial cell types by cell diameter. Arch Kriminol. 2011;228(1-2):11-19.

38. Makadia HK, Siegel SJ. Poly Lactic-co-Glycolic Acid (PLGA) as biodegradable controlled drug delivery carrier. Polymers. 2011;3 (3):1377-1397. doi:10.3390/polym3031377

39. Eniola AO, Hammer DA. Characterization of biodegradable drug delivery vehicles with the adhesive properties of leukocytes II: effect of degradation on targeting activity. Biomaterials. 2005;26(6):661670. doi:10.1016/j.biomaterials.2004.03.003

40. de Prado AP, Perez-Martinez C, Cuellas-Ramon C, et al. Time course of reendothelialization of stents in a normal coronary swine model: characterization and quantification. Vet Pathol. 2011;48(6):11091117. doi: $10.1177 / 0300985811400446$

41. Shigeta T, Aoyama M, Bando YK, et al. Dipeptidyl peptidase-4 modulates left ventricular dysfunction in chronic heart failure via angiogenesis-dependent and -independent actions. Circulation. 2012;126 (15):1838-1851. doi:10.1161/CIRCULATIONAHA.112.096479

42. Joner M, Nakazawa G, Finn AV, et al. Endothelial cell recovery between comparator polymer-based drug-eluting stents. J Am Coll Cardiol. 2008;52(5):333-342. doi:10.1016/j.jacc.2008.04.030

43. Otsuka F, Finn AV, Yazdani SK, Nakano M, Kolodgie FD, Virmani R. The importance of the endothelium in atherothrombosis and coronary stenting. Nat Rev Cardiol. 2012;9(8):439-453. doi:10.1038/nrcardio.2012.64

44. Wilensky RL, March KL, Gradus-Pizlo I, Sandusky G, Fineberg N, Hathaway DR. Vascular injury, repair, and restenosis after percutaneous transluminal angioplasty in the atherosclerotic rabbit. Circulation. 1995;92(10):2995-3005. doi:10.1161/01.cir.92.10.2995

45. Nistala R, Habibi J, Aroor A, et al. DPP4 inhibition attenuates filtration barrier injury and oxidant stress in the zucker obese rat. Obesity. 2014;22(10):2172-2179. doi:10.1002/oby.20833

46. Fadini GP, Avogaro A. Cardiovascular effects of DPP-4 inhibition: beyond GLP-1. Vascul Pharmacol. 2011;55(1-3):10-16. doi:10.1016/j. vph.2011.05.001

47. Sundback CA, Shyu JY, Wang Y, et al. Biocompatibility analysis of poly (glycerol sebacate) as a nerve guide material. Biomaterials. 2005;26 (27):5454-5464. doi:10.1016/j.biomaterials.2005.02.004

48. Akita K, Isoda K, Shimada K, Daida H. Dipeptidyl-peptidase-4 inhibitor, alogliptin, attenuates arterial inflammation and neointimal formation after injury in low-density lipoprotein (LDL) receptordeficient mice. J Am Heart Assoc. 2015;4(3):e001469. doi:10.1161/ JAHA.114.001469 
49. Terawaki Y, Nomiyama T, Kawanami T, et al. Dipeptidyl peptidase-4 inhibitor linagliptin attenuates neointima formation after vascular injury. Cardiovasc Diabetol. 2014;13:154. doi:10.1186/1475-2840-13-80

50. Koyama A, Komori K, Otsuka R, Kajikuri J, Itoh T. Dipeptidyl peptidase 4 inhibitor reduces intimal hyperplasia in rabbit autologous jugular vein graft under poor distal runoff. J Vasc Surg. 2016;63 (5):1360-1370. doi:10.1016/j.jvs.2014.12.048
51. Kagal UA, Angadi NB, Matule SM. Effect of dipeptidyl peptidase 4 inhibitors on acute and subacute models of inflammation in male Wistar rats: an experimental study. Int J Appl Basic Med Res. 2017;7(1):26-31. doi:10.4103/2229-516X.198516

52. Ross R. The pathogenesis of atherosclerosis: a perspective for the 1990s. Nature. 1993;362(6423):801-809. doi:10.1038/362801a0

\section{Publish your work in this journal}

The International Journal of Nanomedicine is an international, peerreviewed journal focusing on the application of nanotechnology in diagnostics, therapeutics, and drug delivery systems throughout the biomedical field. This journal is indexed on PubMed Central, MedLine, CAS, SciSearch ${ }^{\mathbb{R}}$, Current Contents ${ }^{\mathbb{B}} /$ Clinical Medicine,
Journal Citation Reports/Science Edition, EMBase, Scopus and the Elsevier Bibliographic databases. The manuscript management system is completely online and includes a very quick and fair peer-review system, which is all easy to use. Visit http://www.dovepress.com/ testimonials.php to read real quotes from published authors.

Submit your manuscript here: https://www.dovepress.com/international-journal-of-nanomedicine-journal 